\title{
Research on Protection and Inheritance of Oroqen Birch-bark Crafts of Heilongjiang Province
}

\author{
Xiaoli Zhang \\ Heihe University \\ Heihe, China
}

\author{
Hui Xie \\ Heihe University \\ Heihe, China
}

\begin{abstract}
Folk arts in Heilongjiang province have a long history, various categories and profound culture connotation. The birch-bark technology, as an important content of the same arts, is inherited by the Oroqen people in Heilongjiang province with amounts of other folk arts and it belongs to the first batch of national intangible cultural heritage as well, however, these technologies have faded away gradually, even disappeared in their inheritance with the development of the society and progress of the productivity. The several aspects that distribution of the Oroqen birch-bark technology in Heilongjiang province, untraditional birch-bark paintings and craft gifts and the issues occurred in the process of protection and inheritance of Oroqen birch-bark crafts as well as the corresponding countermeasures and suggestions are discussed in this article and it draws a conclusion that the research on countermeasures of Oroqen birch-bark crafts protection has become burning question, which could facilitate the innovation and development of the new modern birch-bark crafts on the basis of protection by making good use of it.
\end{abstract}

Keywords-Heilongjiang Province; Oroqen; birch-bark craft; protection and inheritance

\section{Distribution OF OROQEn BirCh-BARK TeChNOlOGY IN HEILONGJIANG PROVINCE}

Oroqen people, a minority of Heilongjiang province, are known as "Birch Forest Home" due to amounts of birches there. As one of the first national intangible cultural heritage resources, white bark technology \& heritance have a significant research value. In China, birch bark mainly comes from Xinganling, Changbaishan and Zhangguangcai Range, where there are abundant forest resources and provide favorable conditions for the development of the birch-bark technology. Birch-bark crafts are distributed mainly in Heilongjiang River Valley and jointly created by the aboriginals as well as their ancestors lived in that valley. The Oroqen birch-bark technology in Heilongjiang province is intensively distributed in Xinsheng Oroqen minority town, Aihui District, Heihe City, Baiyinna Oroqen minority town, Huma County, Shibazhan Oroqen minority town, Tahe County and Xine Oroqen minority town, Xunke County, of which the Xinsheng Town of Heihe City was awarded "Province-level Ethnic Cultural Tourism Base".

Fund Program: Research on the Protection and Heritance of Oroqen Birch-bark Art in Heilongiang Province, the annual planning project of philosophy and social science research of Heilongjiang Province, number: 15YSE09. Research on Oroqen Birch-bark Art, the art research project of Heihe University, number: YSZ201502. Subsidized by young tip-top talent of science research support plan of Heihe University.

\section{UNTRADITIONAL BIRCH-BARK PAINTINGS AND CRAFT GIFTS}

The Oroqen birch-bark culture has a long history and plays an important role in the production life of the birch-bark products. Birch-bark technology is developed and innovated on the base of traditional technology, giving it a new connotation by making a new technology recreation on the traditional materials, which shows the Oroqen people's wisdom and creation as well as carries forward their culture. Birch-bark crafts compose of birch-bark painting and craft gift. Typical birch-bark paintings include stamping painting, inlaying painting, birch-bark natural texture painting and Chinese painting. Each birch-bark article is also a craft with a strong lasting appeal of modeling design, ornamentation and color, not only overturning the traditional products, but also having a power of making use of discarded things.

\section{A. Birch-bark Stamping Painting}

Press carving, which uses the animals' dentaries to carve the utensils, normally used to express flowers and lace, is one of the traditional technologies of birch-bark utensils processing. Moreover, there's another technology, smoking burn, which uses special tools to conduct smoke burning on the birch-bark utensils directly so as to make beautiful patterns. This kind of birch-bark stamping painting is to develop the traditional press carving and smoking burn, and apply them on the picture. The birch-bark stamping painting work of Tiger made by $\mathrm{Fu}$ Zhanxiang, a birch-bark artist from Raohe County, Heilongjiang Province, is no meticulous and real that it looks just like a fine brushwork more. After observing carefully, we can find that the two technologies of press carving and smoke burning are integrated by the author onto this work, drawing exquisitely and vividly. While another work with religion color, Sophia Church, not only combines its outer form with the traditional birch-bark stamping painting, but also merges the Chinese and Western culture, developing this original birch-bark technology to modernization and even internationalization. People Live in Birch Forest, which has a strong technical effect, is a decorative painting with skillful in workmanship, unique idea, and abundant content and plain taste. Live in Forest combining the classic symbol such as the unique "cactus" living in forest, cradle and deer, descript the "buildings" in the forest and restore its primitive life appearance. Another painting Bonfire, is filled with happiness due to the big harvest after hunting. 


\section{B. Bark-pasted Painting}

Also known as birch-bark inlay painting, it mainly takes advantage of the bark's colors and its layered nature, and makes it by means of cutting and pasting. The birch-bark craft painting alum Talk Heilongjiang in Painting authored by Liu Hengpu, introduces the northern custom of Heilongjiang, integrating original beauty and modern beauty and showing the plain birch, black soil's verve simply and unpretentiously but elegantly. Mo Hongwei born in Xunke County collages birchbarks to innovate, skillfully connects Oroqen birch-bark's culture and technology, expressing the folktales occurred in Oroqen. Origin of the Five Surnames made according to the five surnames of Oroqen and its folklores, perfectly connects its own national culture and the special material carrier, expressing the images of prehistoric disaster, relying in jungle, marrying towards moon, snow cradle and five brothers being talents. He also makes the Walk out from the Birch Forest by modern methods, restoring their submontane life after finishing hunting. In addition to this, the Dagong Shoots the Sun and the Origin of Human Being also use the birch-bark pasting technology to show the stories of Oroqen, which adds a gorgeous miracle.

\section{Birch-bark Natural Texture Painting}

By utilizing the natural problem of the birch-bark and adding the understanding of the bark's nature and technology, it is produced in combination of burning, dyeing and painting and other techniques. Such as the works Earth, constructs the feeling of unbounded and vast of the earth by using birchbark's sun crack texture; the works Birch Forest Far Away in Mountain, combines birch-bark's original texture and the author's imagination to construct a vivid image, extremely expressing the craftsman's fancy; the works Gather shows the lingering charm of the modern ink painting by utilizing uneven texture of the birch-bark; the works Half-moon Pool is created by utilizing the comparison of bark and blank. Chen Jinlai from Oroqen village, Xine town, Xunke County, Heilongjiang Province, utilizes the natural constitute of birch-bark's moss and natural scars to express the plain original appearance of Oroqen and attempts to adopt various technologies such as pasting and burning with hot iron methods to make birch-bark painting. his works, such as The Echo in Mountains, Bilaer Oroqen Shaman Family Tree, The Hunting God and The God of the Mountains received awards for many times. Guan Taofang from Huma County, Heilongjiang Province makes a lot of birch-bark woodcut, pyrography and engraved-cut painting, carrying forward the long history and abundant culture of Oroqen by her works.

\section{Birch-bark Chinese Painting}

By exerting modern art elements and injecting the new technology idea into ancient birch-bark craft, it is a unique style in northern China and it creates the works of landscape and figures on the basis of birch-bark's natural texture, some of which are rough and heroic while some are pure white and exquisite. The differences among the natural burl, tree fur, moss, color and texture of birch-bark is fully utilized and chosen, adding the technologies Chinese painting such as drawing, wrinkling, dotting and dying and after technology processing, this landscape painting-like or figure painting-like craft is made. Every work has a unique effect since the materials for birch-bark Chinese painting is chosen from nature. Tao Dandan from Heihe City, won the title of Folk Artisan Top Ten in the "First China Hangzhou Qinghefang Folk Arts Festival", whose works of Water from Sky, Lake and Fall show the far mountain and beauty in her hometown, Heilongjiang Province, carrying forwards the cultural spirit of Heilong River. This young craftsman of birch-bark technology let us see not only the qualified successor of birch-bark technology, but also see the inheritance and innovation of the technology.

\section{E. New Birch-bark Crafts}

The traditional birch-bark products are composed of weapon and fishing \& hunting tools, birch-bark living containers, birch-bark living tools, birch-bark boat, birch-bark house, birch-bark religious articles, birch-bark funerary articles and birch-bark toys. In recent years, new birch-bark articles occurred and the familiar ones are birch-bark painting, birchbark paper-cuts, birch-bark four treasures of the study, birchbark chess and birch-bark book etc. which can be classified as crafts.

Principle of "practical is beautiful" tells us that the first nature of birch-bark product is practical and it is not only made to meet the demand of production and living but also meet our own aesthetic requirements. In the long-term development of society, birch-bark product makers are not just satisfied with the actual demands and they give new aesthetic ideology to birch-bark products more. With the arriving of the new age, the practical functions of the birch-bark products has withdrawn from the historical stage while its aesthetic value is more and more outstanding, it become more delicacy, integrated with various types of technologies such as sculpting, painting and dyeing. In addition, due to diversification of birch-bark technology, there are some other birch-bark crafts developing in the tourist goods and souvenirs among the gift $\&$ craft market and make contribution.

The modern new birch-bark crafts and imitative birch-bark containers reserving original favor not only have birch-bark's practice function but also play its manufacturability to extreme, such as the new birch-bark craft Birch-bark Chess, which combines the traditional birch-bark and entertainment tools chess and integrates the ancient bark culture and recreation well according to the natural color, character and the characteristics of toughness and gradation of the bark, making people find everything new and fresh by means of stickup, hollowing, inlay and carving technology, so that play a better role of the modernity of the birch-bark crafts, by which more and more people know birch-bark crafts and understand it, thus like it as well as make a bigger development and better sales market for birch-bark crafts.

\section{TECHNOLOGY PROTECTION AND INHERITANCE ISSUES OF OROQEN BIRCH-BARK}

The birch-bark crafts coagulate the collective intelligence of Oroqen people, show the production custom system of Oroqen people and inherit the long hunting culture of Oroqen. 
The birch-bark crafts not only witness Oroqen's ancient hunting civilization, but also an important part of Oroqen culture, at the same time, the birch-bark technology of Oroqen is moving on with the variation of the social and ecological environment while the technology protection and inheritance issues of birch-bark need to be solved urgently.

\section{A. The Raw Materials Are Scanty}

Though the birch-bark technology of Oroqen belongs to national intangible cultural heritage, its inheritance is not optimistic. Birch-bark craft is mainly made of birch-bark, but it is hard to find proper raw materials for making birch-bark craft due to unreasonable development of forest resources and various natural and man-made disasters. Oroqen people never break the inner bast when they peel birch-bark due to birches have natural renewability and the peeled birches will grow new bark in next spring. However, the other people, who know little law on this, cut the bark with over strength, wounding the inner bast and resulting in the birches' death. Adding the unreasonable and predatory development and destruction on the whole forest ecosystem and resource made by people who destroy the tree resources and ecological environment, the oldgrowth forest is disappeared basically.

\section{B. The To-and-Fro Trip Culture Has Disappeared}

With the society progress and development of productivity, adding the serious destruction on the natural environment of Great Khingan, Oroqen's to-and-fro trip loses its support so that the birch-bark culture loses its fountain head and is hang by a thread. The rapid development of society and economy at the cost of the loss and destruction of natural resources, which is to kill the golden goose and drain the pond to get all fish, is more harm than good. At present, more and more people start to participate in the nature \& ecological balance protection procession in worldwide and most of them have put the nature protection into practice.

\section{MEAsures AND SUGgestions ON THE PROTECTION OF OROQEN BIRCH-BARK TECHNOLOGY OF HEILONGJIANG PROVINCE.}

The Oroqen industrial arts of Heilongjiang Province compose of paper-cuts, hides, fish skin and other technological forms with abundant resources and various contents. The writer goes deep into Oroqen area, Xinsheng village, Heihe City, Heilongjiang Porivce and Xine Oroqen National Township of Xunke County to study the ancient Oroqen culture and conduct fieldwork on the existed problems and protection by visiting their elegant and plain birch-bark products and the process of women making birch-bark products. And the following aspects of the protection measures of Oroqen birch-bark technology is provided by the writer on the basis of those seen and heard as well as protection situations.

- The government should work out protection measures and policies to strengthen protection. At the present, the Oroqen agglomeration of Heilongjiang Province has established intangible cultural heritage protection center and related policies and specific measures of protection, however, it is hard to realize in most cases, since the heritance of birch-bark traditional technology relies on the inheritors and a few specialists, which needs to put the protection measures into practice and makes the protection and publicity in place well. The records of protection on birch-bark technology and every birch-bark craft should be made carefully, such as made-time, maker, technology, ornamentation, function and moral, then build data bank to number them and preserve in categories. The favorable works should be exhibited to carry forward the Oroqen culture or the civil traditional culture of Heilongjiang Province to the world, acting on international convention and promoting the development of cultural industries of Heilongjiang Province.

- Build Oroqen birch-bark museum and orginal ecology conservation area. The minorities in Heilongjiang Province, including Oroqen, Daur, Hezhen, Mongols and Manchu, of which the architecture, carving, clothes, crafts and custom play an important role in culture and need to be preserved by means of birch-bark museum and original ecology conservation area to protect the civil heritance and traditional custom of Oroqen. At the present, the birch-bark cultural museum of northern hunting nation established by Aoluguya village is the only birch-bark cultural museum in China, which builds the foundation for the people over the world to know Oroqen culture.

- Improve the intangible cultural heritage protection mechanism at national, provincial, municipal, prefectural and village levels, which will contribute to the inheritance and protection of birch-bark technology. The protection list is relative to corresponding protection system, being incident with one other that the protection list is the resources while the protection system is the guidance and implementation methods of the policies. The birch-bark technology protection organization should be built completely from the state to local, which contributes to the development and implementation of the birch-bark technology protection work.

- Strengthen the integration of the resources and funds of civil art. The civil art resources in Heilongjiang area are abundant but lack of good integration and sharing. Heilongjiang, which is in a more completed regional cultural system and is a relative completed regional cultural system per se, for example, the Oroqen birchbark technology of Heilongjiang and Ewenki bark of Daur, both belong to different civil technologies of same nation so that there are many things in common on the materials and craftsmanship. These resources can be made to be birch-bark technology brand of different areas and peoples, such as the "birch-bark technology of Heilongjiang three minority nationalities". With respect to capital, it needs not only the support of the government, but also the support of non-government funds as well as the recycle of the productive income, conducting uniform planning and management of the funds, so as to provide a stronger 
capital guarantee for the protection of birch-bark technology.

- Pay more attention to the civil artist and the inheritors of birch-bark. In the case of the fact that more and more birch-bark artists run away and the birch-bark is in imminent danger, the government should pay more attention to birch-bark artists and inheritors on the basis of the protection of birch-bark technology in Heilongjiang Province. The in being birch-bark artists, Guo Fulin, Mo Hongwei, Guo Dandan and so on, can be introduced into the applied arts curriculum of the college with the birch-bark technology, making more young men know and learn to make birch-bark crafts and taking the college as inheritance base of birch-bark technology. In addition, the government should make great effort to contribute to hold classes of birch-bark technology, so as to make the birch-bark technology be inherited and have qualified successors.

\section{CONCLUSION}

For sixty years, the Oroqen people have lived here, which means the traditional resident building "Xianren column" has been historical memory of them. Early in their resident life, the Oroqen built "Xianren column" in front of their houses while now the columns only can be seen in museum and Custom Park. However, Oroqen people still have strong national complex that the appearance of the built the third generation resident buildings in Xinsheng Oroqen village, Aihui District, Heihe City is still designed imitating "Xianren column", by which way they wish that can keep their national culture for long. In allusion to the traditional handicraft, birch-bark technology, the best method of inheritance protection is to develop and recycle the resources from the perspective of art, which is in accordance with the requirements of birch-bark technology own characteristics and resource transformation and hope the Oroqen birch-bark crafts of Heilongjiang Province, can be protected and inherited in brand new forms and connotation, just like the Oroqen traditional building "Xianren column".

\section{REFERENCES}

[1] Wang Yizhang, Wang Tiefeng. Legacy of White Birch: Birth-bark Culture in Northern China. Heilongjiang People's Publishing House, 2011

[2] Bai Xiaoxia. Protection and Inheritance of Intangible Cultural Heritage in the perspective of art design-taken birch-bark technology for example. Decoration, March 2015

[3] Zhang Jingming. The Relationship between Protection Measures of Northeastern Art Intangible Cultural Heritage and Cultural Creative Industry. Jiangnan University Journal (Humanities and social sciences version), May 2013.

[4] Zhang Xiaolin. Analysis on birch-bark Pattern of Oroqen People Theme. Popular Literature, October 2011.

[5] Zhang Xiaoli, Liu Yang. Discussion on Value Characteristic and Inheritance Strategy of Oroqen Birch-bark Art. Art Panorama, November 2015.

[6] Liu Yang, Zhang Xiaoli. Survey and Analysis on Sino-Russian Tourist Handicrafts Market. Popular Literature, June 2015. 